\title{
Tache Noire in a Patient with Acute Q Fever
}

\author{
Vito Fiore $^{a}$ Fabiola Mancinic $^{c}$ Alessandra Ciervo $^{c}$ Paola Bagella ${ }^{a}$ \\ Francesca Peruzzu $^{a}$ Giuseppe Nunnarid ${ }^{d}$ Giovanni Andrea Deianab

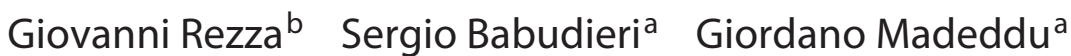

Units of ${ }^{\mathrm{a}}$ Infectious Diseases and ${ }^{\mathrm{b}}$ Neurology, Department of Clinical and Experimental Medicine, University of Sassari, Sassari, ' Department of Infectious, Parasitic and Immunomediated Diseases, Istituto Superiore di Sanità, Rome, and ${ }^{\mathrm{d} D i v i s i o n}$ of Infectious Diseases, Department of Clinical and Experimental Medicine, University of Messina, Messina, Italy

\section{Significance of the Study}

- Tache noire is the pathognomonic sign of Mediterranean spotted fever (MSF), caused by Rickettsia conorii, and of MSF-like illness, but it is not a clinical feature of Q fever. We report a rare case of Q fever with tache noire.

\section{Keywords}

Tache noire $\cdot \mathrm{Q}$ fever · Mediterranean spotted fever

\begin{abstract}
Objective: To describe a rare case of acute $Q$ fever with tache noire. Clinical Presentation and Intervention: A 51-year-old man experienced acute $Q$ fever showing tache noire, generally considered a pathognomonic sign of Mediterranean spotted fever (MSF) and MSF-like illness, but not a clinical feature of $\mathrm{Q}$ fever. The patient was treated with doxycycline 100 mg every 12 h. Conclusion: In the Mediterranean area, tache noire should be considered pathognomonic of MSF but it should not rule out $\mathrm{Q}$ fever. Clinical diagnosis should be supported by accurate laboratory diagnostic tests to guide proper management.

(c) 2018 The Author(s)

Published by S. Karger AG, Basel
\end{abstract}

\section{Introduction}

Coxiella burnetii is an obligate, intracellular gramnegative bacterium which infects several vertebrate species. In humans, it is the causative agent of $\mathrm{Q}$ fever. $\mathrm{Q}$ fever may be transmitted via inhalation of contaminated aerosols and ingestion of contaminated milk. The possibility of C. burnetii also being transmitted to humans via ticks was reported in 1947 [1]. Q fever is endemic in large parts of Europe, and studies conducted between 1970 and 2009 showed that $10-30 \%$ of rural populations in different countries have antibodies against $C$. burnetii, as highlighted by the ECDC technical report in 2010 [2]. Acute $\mathrm{Q}$ fever has a sudden onset, with fever, headache, chills, cough, and myalgia being the most common symptoms. The clinical picture includes flu-like illness, pneumonia, and hepatitis.

\section{KARGER}

E-Mail karger@karger.com www.karger.com/mpp

\section{The Author(s) \\ Published by S. Karger AG, Basel}

Karger

Open access

This is an Open Access article licensed under the Creative Commons Attribution-NonCommercial-4.0 International License (CC BY-NC) (http://www.karger.com/Services/OpenAccessLicense), applicable to the online version of the article only. Usage and distribution for commercial purposes requires written permission.
Vito Fiore (MD)

Unit of Infectious Diseases, Department of Clinical and

Experimental Medicine, University of Sassari, Viale San Pietro 43c, Sassari IT-07100 (Italy)

E-Mail vitofiore30010516@gmail.com 
Table 1. Serology tests performed on a patient with tache noire during acute Q fever

\begin{tabular}{lll}
\hline Serology test & First evaluation (at time of first visit) & Second evaluation (after 2 weeks) \\
\hline Rickettsia spp. $^{1}$ & $\operatorname{IgM}<1: 64$ IgG $<1: 128$ & $\operatorname{IgM}<1: 64$ IgG $<1: 128$ \\
Anaplasma phagocytophilum $^{2}$ & $\operatorname{IgM}<1: 20$ IgG $<1: 40$ & $\operatorname{IgM}<1: 20$ IgG $<1: 40$ \\
Ehrlichia canis $^{3}$ & $\operatorname{IgM}<1: 20$ IgG $<1: 40$ & $\operatorname{IgM}<1: 20$ IgG $<1: 40$ \\
Bartonella henselae $^{4}$ & $\operatorname{IgM}<1: 20$ IgG $<1: 40$ & $\operatorname{IgM}<1: 20$ IgG $<1: 40$ \\
Coxiella burnetii & IgM $1: 50$ phase I antigen & IgG $1: 320$ phase II antigen \\
& IgG: $1: 50$ phase II antigen & IgG $1: 80$ phase I antigen \\
\hline
\end{tabular}

${ }^{1}$ Cut-off: IgM 1:64, IgG 1:128; ${ }^{2}$ cut-off: IgM 1:20, IgG 1:40; ${ }^{3}$ cut-off: IgM 1:20, IgG 1:40; ${ }^{4}$ cut-off: $\operatorname{IgM} 1: 20, \operatorname{IgG} 1: 40 ;{ }^{5}$ cut-off: IgM and IgG: 1:50 phase I and II antigens.

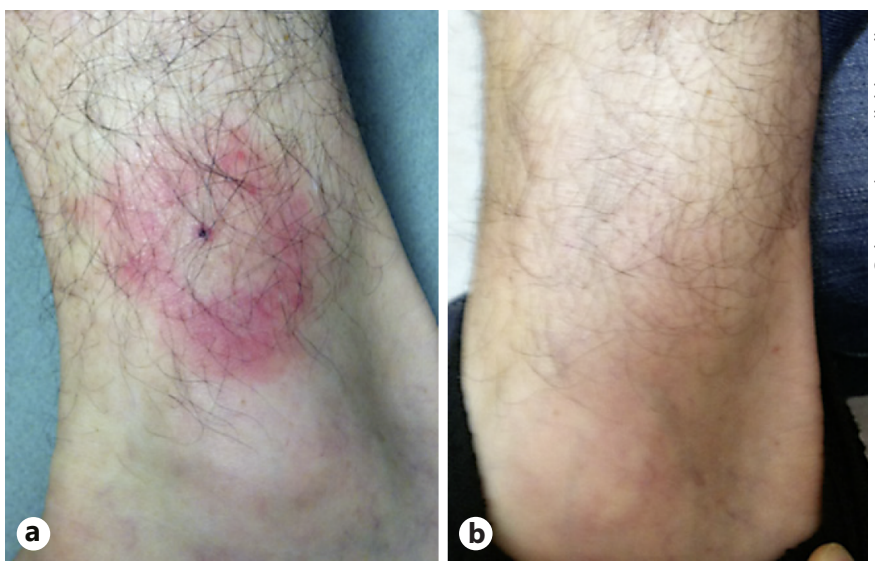

Fig. 1. a Tache noire at the lower medial surface of the right leg surrounded by circular erythema. b Complete remission after 14 days of doxycycline treatment.

Tache noire is considered a pathognomonic sign of Mediterranean spotted fever (MSF) and MSF-like illness, which are transmitted by ticks, but it is not considered a clinical feature of Q fever.

\section{Case Report}

We report a case of acute $\mathrm{Q}$ fever with tache noire in a 51-yearold man from Sassari, Northwestern Sardinia, where Q fever represents $8 \%$ of acute febrile illnesses in the spring/summer period [3].

The patient lived in a periurban area, and was referred to the Infectious Disease Unit of the University of Sassari in June 2012, with a low fever $\left(37.5^{\circ} \mathrm{C}\right)$, headache, general malaise, myalgia, and a nonproductive cough which had started 7 days before. Physical examination revealed a dark crusty skin lesion compatible with inoculation eschar, surrounded by edema and a circular erythema (Fig. 1). No maculopapular rash was present. The patient recalled a tick bite. Cardiopulmonary and abdominal physical examinations were normal. Laboratory results showed a relative lymphomonocytosis and a slight increase in C-reactive protein. The remaining parameters were within the normal range. Based on a clinical suspicion of MSF-like illness, the patient was started on doxycycline $100 \mathrm{mg}$ every $12 \mathrm{~h}$.

Serological analyses for all Rickettsia spp., Anaplasma phagocytophilum, Ehrlichia canis, Bartonella henselae, and C. burnetii were performed by immunofluorescence antibody assay (IFA) at the first clinical evaluation, and then repeated after 2 weeks. Enzyme-linked immunosorbent assay (ELISA) for Rickettsia conorii and Borrelia spp. was also performed. The first sample showed anti-Coxiella IgG phase II and I antibody titer of 1:50, but the second test was clearly positive, with an antibody titer $>6$ times higher than in the previous test (anti-Coxiella IgG phase II $=1: 320$ and phase $\mathrm{I}=1: 80$ ). The search for other antibacterial antibodies was negative in both samples (Table 1), as were the ELISA for $R$. conorii and Borrelia spp.

Additionally, a skin biopsy of the tache noire collected in PBS buffer and a whole-blood sample were obtained prior to antibiotic therapy. DNA was extracted for genomic detection of Rickettsia, using molecular methods based on real-time PCR. The primers (forward) TCGCAAATGTTCACGGTA CTTT and (reverse) TCGTGCATTTCTTTCCATTGTG were used to identify the genus Rickettsia that includes the spotted fever group (SFG) and the typhus group (TG), and to amplify the gene gltA which codes for the citrate synthase enzyme [4]. All of these tests were negative.

The patient completed a 14-day course of doxycycline at home, with complete clinical remission (Fig. 1).

\section{Discussion}

Our case suggests that $C$. burnetii was the etiological agent in a patient with tache noire and suspected MSFlike illness. This finding has important clinical implications. Rickettsioses are endemic in Sardinia, where MSF is a common summertime fever mostly caused by R. conorii, and sometimes by R. monacensis [5]. Thus, Q fever was, to some extent, an unexpected diagnosis in a patient with fever and tache noire. In particular, this case suggests 
that tache noire, generally considered to be the pathognomonic sign of Rickettsia infection, may also be seen in acute $Q$ fever.

Differential diagnosis is important, as infections due to $C$. burnetii have a different clinical management from other Rickettsioses in terms of the duration of therapy, particularly if complicated. In our case, a misdiagnosis of $\mathrm{Q}$ fever would have led to a shorter antibiotic treatment, with the possible occurrence of further complications and the potential risk of developing a chronic infection.

$\mathrm{Q}$ fever is not usually considered as being a tick-borne disease; however, several published studies suggest that $C$. burnetii may indeed be found in ticks in Mediterranean countries, including Italy. For example, in a study conducted in Algeria, 268 ticks were evaluated, using realtime PCR, standard PCR, and sequencing, for the presence of Bartonella spp., Rickettsia spp., Borrelia spp. and C. burnetii. DNA from C. burnetii was identified in 3/19 (15.8\%) Ixodes vespertilionis ticks [6], and a study conducted in Sardinia found evidence of C. burnetii infection in ticks from mammal hosts [7].

Finally, ticks seem to play a fundamental role in the spread of $C$. burnetii among various vertebrates, such as rodents, lagomorphs, and wild birds, as reviewed by Por- ter et al. [8], highlighting, again, the need for more knowledge about the role of these arthropods in the natural cycle of C. Burnetii, particularly concerning the possible transmission of $\mathrm{Q}$ fever to humans.

$\mathrm{Q}$ fever is considered to be an airborne zoonotic disease, but ticks such as Rhipicephalus microplus or R. sanguineus are also suspected to be involved in Q fever epidemiology as potential vectors [9]. We do not know what species of tick was involved in our case, but given its countrywide distribution, we speculate that $R$. sanguineus may have been responsible.

In conclusion, in the Mediterranean area tache noire should be considered pathognomonic of MSF, but its presence should not rule out a diagnosis of $\mathrm{Q}$ fever, and the possibility of concomitant or consecutive infections should also be considered [10]. Of course, clinical diagnosis should be supported by accurate laboratory diagnostic tests in order to rapidly differentiate between possible pathogens and to guide a proper management.

\section{Disclosure Statement}

The authors report no conflicts of interest.

\section{References}

1 Eklund CM, Parker RR, Lackman DB: A case of Q fever probably contracted by exposure to ticks in nature. Public Health Rep 1947;62: 1413-1416.

2 Technical Report: Risk Assessment on Q Fever. Stockholm, European Centre for Disease Prevention and Control, 2010.

-3 Madeddu G, Fiore V, Mancini F, et al: Mediterranean spotted fever-like illness in Sardinia, Italy: a clinical and microbiological study. Infection 2016;44:733-738.

$\checkmark 4$ Paris DH, Blacksell SD, Stenos J, et al: Realtime multiplex PCR assay for detection and differentiation of rickettsiae and orientiae.
Trans R Soc Trop Med Hyg 2008;102:186193.

5 Madeddu G, Mancini F, Caddeo A, et al: Rickettsia monacensis as cause of Mediterranean spotted fever-like illness, Italy. Emerg Infect Dis 2012;18:702-704.

6 Leulmi H, Aouadi A, Bitam I, et al: Detection of Bartonella tamiae, Coxiella burnetii and Rickettsiae in arthropods and tissues from wild and domestic animals in northeastern Algeria. Parasit Vectors 2016;9:27.

7 Satta G, Chisu V, Cabras P, et al: Pathogens and symbionts in ticks: a survey on tick species distribution and presence of tick-trans- mitted micro-organisms in Sardinia, Italy. J Med Microbiol 2011;60:63-68.

$>8$ Porter SR, Czaplicki G, Mainil J, et al: Q Fever: current state of knowledge and perspectives of research of a neglected zoonosis. Int J Microbiol 2011;2011:248418.

$\checkmark 9$ Duron O, Sidi-Boumedine K, Rousset E, et al: The importance of ticks in Q fever transmission: what has (and has not) been demonstrated? Trends Parasitol 2015;31:536-552.

10 Rolain JM, Gouriet F, Brouqui P, et al: Concomitant or consecutive infection with Coxiella burnetii and tickborne diseases. Clin Infect Dis 2005;40:82-88. 